\title{
PENGEMBANGAN BUDAYA SEKOLAH BERBASIS KATOLIK
}

\author{
Atika*, Piter Joko Nugroho, Sumarnie \\ FKIP, Universitas Palangka Raya \\ *E-mail: sdn06mdrj@gmail.com
}

\begin{abstract}
Abstrak: Penelitian kualitatif dengan rancangan studi kasus ini bertujuan untuk mendeskripsikan tentang pengembangan budaya sekolah berbasis agama Katolik pada Sekolah Menengah Pertama (SMP) Maria Gorreti Semarang (MGS), dilihat dari aspek: 1) Proses lahirnya budaya sekolah berbasis agama Katolik, 2) Nilai-nilai karakter budaya sekolah berbasis agama Katolik, 3) Strategi pengembangan budaya sekolah berbasis agama Katolik, 4) Faktor pendukung dan kendala yang dihadapi dalam pengembangan budaya sekolah berbasis agama Katolik, dan 5) Upaya untuk meminimalisir kendala yang dihadapi dalam pengembangan budaya sekolah berbasis agama Katolik. Pengumpulan data dilakukan dengan metode wawancara mendalam, observasi partisipan, dan studi dokumentasi. Penetapan sumber data dilakukan dengan teknik purposive sampling. Analisis data dilakukan dengan menggunakan pola interaktif Miles dan Huberman (1994) Pengecekan keabsahan data dilakukan dengan menggunakan derajat kepercayaan (credibility) melalui teknik triangulasi baik sumber maupun metode. Hasil penelitian menunjukkan bahwa pengembangan budaya sekolah berbasis agama Katolik pada SMP MGS dilaksanakan dengan mengacu pada nilai-nilai filosofis pendiri (founding father) Yayasan Marsudirini Semarang. Nilai-nilai filosofis para pendiri sekolah tersebut menjadi landasan utama dalam pembentukan karakter budaya sekolah. Dengan strategi pengembangan budaya sekolah yang direalisasikan dalam berbagai program dan kegiatan yang ditujukan bagi guru dan tenaga kependikan serta para peserta didik mampu menjadikan SMP MGS menjadi sekolah berprestasi sekaligus sekolah favorit di Kota Semarang.
\end{abstract}

Kata Kunci: Pengembangan; Budaya Sekolah, SMP Maria Gorreti Semarang.

\begin{abstract}
Qualitative research with a case study design aims to describe the development of Catholicbased school culture in the Middle School (SMP) Maria Gorreti Semarang (MGS), viewed from aspects: 1) the birth process of Catholic-based school culture, 2) values the character of Catholic-based school culture, 3) the strategy of developing a Catholic-based school culture, 4) supporting factors and obstacles faced in developing a Catholic-based school culture, and 5) efforts to minimize the constraints faced in developing a Catholic-based school culture. Data collection is done by methods: in-depth interviews, participant observation, and study documentation. Determination of data sources is done by using purposive sampling technique. Data analysis was performed using the interactive patterns of Miles and Huberman (1994). Checking the validity of the data is done by using a degree of credibility through both source and method triangulation techniques. The results of study showed that he development of Catholic-based school culture in the MGS Middle School was carried out with reference to the founding father's philosophy of the Semarang Marsudirini foundation. The philosophical values of the founders of the school became the main foundation in shaping the school's cultural character. With the strategy of developing a school culture that is realized in various programs and activities aimed at teachers and education personnel and students, it is able to make MGS Middle School become an outstanding school as well as a favorite school in the city of Semarang.
\end{abstract}

Keywords: Development, School Culture, SMP Maria Gorreti Semarang.

\section{PENDAHULUAN}

Pendidikan merupakan kunci utama dalam upaya mensukseskan pembangunan suatu bangsa. Seringkali kebesaran suatu bangsa diukur dari sejauhmana masyarakatnya mengenyam pendidikan. Semakin tinggi pendidikan yang dimiliki oleh suatu masyarakat, maka semakin majulah bangsa tersebut (Sonhadji, 2007).
Pendidikan juga dapat diartikan sebagai upaya transmisi budaya dalam bentuk informasi spesifik melalui proses mental dan rasionalitas yang mengarahkan peserta didik untuk memperoleh pengalaman dalam rangka mencapai kemampuan tertentu serta martabat yang mulia, atau dapat dikatakan values and culture. Dalam pendidikan aspek rasionalitas, martabat, etika dan 
estetika sangat ditekankan karena anakanak sekarang adalah pemimpin dan pelaku-pelaku perjalanan bangsa Indonesia di masa depan (Sonhadji, 2012).

Kebudayaan dan pendidikan memiliki hubungan timbal balik sebab kebudayaan dapat dilestarikan dan dikembangkan dengan jalan mewariskan kebudayaan dari generasi ke generasi penerus melalui pendidikan, baik secara formal, informal dan non formal. Sebaliknya bentuk, ciri-ciri dan pelaksanaan pendidikan ikut ditentukan oleh kebudayaan masyarakat dimana proses pendidikan itu berlangsung (Tirtahardja dan Sulo, 2005). Perihal senada juga diungkap Tilaar (2000) pendidikan tidak dapat dipisahkan dari keseluruhan masyarakat atau dengan kata lain merupakan sebagian dari kebudayaan. Dengan demikian tujuan pendidikan yang selama ini hanya berfokus pada pembentukan intelektual semata-mata haruslah diubah menjadi pembentukan spektrum intelegensi manusia, oleh sebab itu program pendidikan di sekolah tidak hanya ditujukan untuk kepada peserta didik untuk memiliki intelegensi akademik saja melainkan harus menyentuh pada seluruh perkembangan berbagai macam intelegensi seperti intelegensi emosional, intelegensi estetik, intelegensi inter-personal dan seterusnya. Dengan memperhatikan keseluruhan per-kembangan tersebut diharapkan mutu pendidikan sekolah dapat ditingkatkan.

Kualitas pendidikan sekolah merupakan salah satu hasil dari budaya sekolah yang kuat (Dewi, 2015). Hanushek (dalam Sudrajat, 2010); Depdiknas (dalam Siswanto, 2017) menyatakan upaya peningkatan kualitas pendidikan sekolah dapat dibangun melalui 2 (dua) strategi utama, yaitu strategi yang berfokus pada: (1) dimensi struktural dan (2) dimensi kultural. Penerapan strategi secara struktural sudah sering dilakukan melalui berbagai pengaturan, rekayasa sistem penyampaian informasi yang relevan dengan tuntutan dan kebijakan, pergantian kurikulum, serta berbagai pelatihan,namun hasilnya dipandang belum cukup memuaskan. Oleh karena itu agar mutu pendidikan sekolah meningkat selain dilakukan secara konvensional perlu pula dilakukan dengan pendekatan inkonvensional yaitu melalui strategi dimensi kultural sebagai salah satu faktor yang menentukan peningkatan mutu sekolah (Hafidhuddin dan Tanjung, 2003). Berbagai studi lainnya juga menunjukkan bahwa strategi yang bersifat budaya atau dinamakan pengembangan budaya sekolah berpengaruh besar terhadap perilaku belajar para siswa di sekolah. Studi yang dilakukan Jones dan Richard (dalam Siswanto, 2017) tentang "The School Culture Inventory: A Tool for Identifying Values, Setting Goals and Bringing about School Improvement pada sekolah-sekolah di Toronto menunjukan sekolah-sekolah berprestasi pada umumnya dapat dikenali dari budaya organisasinya yang kuat dan positif yang pada akhirnya bermuara pada pencapaian tujuan sekolah.

Budaya sekolah (school culture) merupakan salah satu unsur sekolah yang penting dalam mendukung peningkatan prestasi dan mutu pendidikan (Husni, 2015). Budaya sekolah merupakan nilai, kepercayaan dan norma yang diterima bersama dan dilaksanakan dengan penuh kesadaran sebagai perilaku alami dan dibentuk oleh lingkungan dengan menciptakan pemahaman yang sama pada seluruh sivitas sekolah (Dewi, 2015). Depdiknas (2007) menyatakan budaya sekolah merupakan nilai-nilai dominan yang didukung oleh sekolah atau falsafah yang menuntut kebijakan sekolah terhadap semua unsur dan komponen sekolah termasuk stakeholder pendidikan, seperti cara melaksanakan pekerjaan di sekolah serta asumsi atau kepercayaan dasar yang dianut oleh personil sekolah yang menjadi ciri khas, karakter atau watak dan citra sekolah tersebut di masyarakat luas.

Satuan pendidikan yang memiliki budaya sekolah yang kuat sebagai filter dalam era globalisasi dan perkembangan kemajuan IPTEK dewasa ini menjadi pilihan mayarakat untuk menyekolahkan anak-anak mereka. Studi yang dilakukan 
Sunyoto (2010) menunjukkan tingginya minat masyarakat terhadap sekolah yang memiliki budaya sekolah berbasis agama. Kepercayaan dari masyarakat pada era globalisasi dewasa ini untuk menyekolahkan anaknya pada sekolah yang berbasis religi menunjukkan trend peningkatan yang luar biasa. Alasan mendasarkan yang menyebabkan tingginya animo masyarakat untuk menyekolahkan anak mereka pada sekolah-sekolah berbasis agama adalah disebabkan antara lain oleh: (1) kekhawatiran orang tua terhadap dampak negatif globalisasi, dan (2) para orang tua menghendaki putra putrinya tumbuh menjadi anak yang baik, cerdas, patuh dan terampil (Dewi, 2015; Syafei, 2006); sehingga dewasa ini banyak sekali dapat kita jumpai sekolah-sekolah baik negeri maupun swasta yang menampilkan/menonjolkan aspek keimanan dan ketaqwaan terhadap Tuhan Yang Maha Esa sebagai hal mendasar yang tertuang dalam visi dan misi sekolah, yang dibalut dalam bingkai religius agama seperti Islam, Kristen, Katolik, Hindu maupun Budha, sebagai landasan dalam melaksanakan proses pendidikan dan pengelolaan sekolah.

Salah satu sekolah swasta yang memiliki budaya sekolah berbasis religius dan merupakan salah satu sekolah terbaik di Kota Semarang adalah SMP Maria Gorreti Semarang (MGS). SMP MGS merupakan salah satu sekolah berbasis agama Katolik yang menjadi sekolah favorit swasta di kota Semarang. SMP MGS merupakan sekolah milik Yayasan Marsudirini. Yayasan Marsudirini merupakan suatu lembaga berbada hukum milik suster-suter OSF yang mengelola pendidikan dasar dan menengah. Visi SMP MGS adalah "Menjadi Pusat Pengembangan Kecerdasan yang Dilandasi Semangat Cinta Kasih". Dalam upaya mewujudkan visi tersebut, SMP Mari Gorreti Semarang memiliki Misi: (1) mewujudkan sikap bersaudara dengan sesama dan alam ciptaan Tuhan, (2) mengembangkan kepribadian peserta didik secara utuh, (3) meningkatkan prestasi peserta didik. Sesuai dengan visi dan nisi yang tercantum, SMP MGS menjadikan peserta didik cerdas dalam intelektual dan memiliki pribadi yang santun, disiplin, dan iman Katolik yang tangguh. Dalam upaya menghasilkan peserta didik cerdas dalam intelektual dan memiliki pribadi yang santun, disiplin, dan iman Katolik yang tangguh tersebut, maka pengelolaan sekolah termasuk di dalamnya terkait dengan pengelolaan pembelajaran baik di dalam maupun di luar kelas selalu berupaya untuk menanamkan pendidikan karakter bagi peserta didik antara lain dalam bentuk kegiatan yang dapat menumbuhkan: (1) semangat religiusitas dan kebangsaan, (2) kesederhanaan, (3) semangat berbelarasa, (4) budaya peduli lingkungan sekitar, (5) budaya kasih, (6) budaya kerapian dan keindahan, dan (7) rasa memiliki sekolah/cinta almamater (SMP Maria Gorreti, 2017). Dampak positif dari budaya sekolah yang kuat tersebut adalah dengan berbagai capaian dan prestasi yang diraih sekolah baik dalam dalam bidang akademik maupun non akademik.

"SMP Maria Gorreti merupakan sekolah dengan Akreditasi A. Sekolah kami seringkali meraih prestasi juaradalam bidang akademik maupun non akademik. Sekolah kami ini juga merupakan sekolah lingkungan sehat (LSS) tingkat Provinsi Jawa Tengah serta Sekolah Adiwiyata tingkat Kota Semarang sejak tahun 2012 hinga sekarang. Berbagai capaian sekolah ini salah satunya merupakan realisasi dari budaya sekolah yang kuat di sekolah kami" (KS.SMPMGS)

Danim (2007) menyatakan hasil pendidikan dipandang bermutu jika mampu melahirkan keunggulan akademik dan ekstrakulikuler pada peserta didik yang dinyatakan lulus untuk satu jenjang pendidikan atau menyelesaikan program pembelajaran tertentu. Keunggulan akademik dinyatakan dengan nilai yang dicapai oleh peserta didik. Keunggulan ekstrakulikuler dinyatakan dengan aneka jenis keterampilan yang diperoleh siswa selama mengikuti program ekstrakulikuler. Di luar kerangka itu, mutu luaran juga dapat 
dilihat dari nilai-nilai kehidupan yang dianut, moralitas, dorongan untuk maju, dan lain-lain yang diperoleh peserta didik selama menjalani pendidikan. Budaya sekolah yang sehat memberikan peluang sekolah dan warga sekolah yang berfungsi secara optimal, bekerja secara efisien, energik, penuh vitalitas, memiliki semangat tinggi, dan akan mampu terus berkembang, oleh karenanya budaya sekolah perlu untuk terus dikembangkan.

$\begin{array}{ccr}\text { Daryanto } & (2015) & \text { menyatakan } \\ \text { pengembangan } & \text { budaya } & \text { sekolah }\end{array}$
memberikan banyak manfaat bagi satuan pendidikan, antara lain: (1) menjamin kualitas kerja yang lebih baik, (2) membuka seluruh jaringan komunikasi dari segala jenis dan level baik komunikasi vertikal maupun horizontal, (3) menciptakan kebersamaan dan rasa saling memiliki yang tinggi, (4) meningkatkan solidaritas dan rasa kekeluargaan, dan (5) dapat beradaptasi dengan baik terhadap perkembangan IPTEK. Lebih lanjut dikatakan pengembangan budaya sekolah juga memberikan manfaat pula baik bagi individu (pribadi) dan kelompok khususnya dalam hal untuk meningkatkan kepuasan kerja, belajar dan berprestasi, peningkatan kedisiplinan, serta memberikan berbagai dampak positif lainnya bagi sekolah dan masyarakat; sehingga hal-hal positif dari budaya sekolah tersebut akan menumbuhkan trust atau kepercayaan masyarakat terhadap sekolah.

Berdasarkan konteks penelitian tersebut diatas tentang: (1) mutu pendidikan sekolah merupakan harapan dari semua masyarakat, (2) upaya memperbaiki dan mengembangkan kualitas/mutu sekolah salah satunya dapat dilakukan melalui strategi dimensi kultural/budaya sebagai alternatif untuk mengoptimalkan strategi dimensi struktural yang hasilnya dipandang belum cukup memuaskan, 3) berbagai studi menunjukkan bahwa strategi yang bersifat budaya menujukkan dampak positif dalam peningkatan mutu pendidikan dan pencapaian tujuan sekolah, 4) SMP MGS merupakan sekolah berprestasi dengan budaya sekolah yang kuat berbasis agama
Katolik, maka penelitian tentang "Pengembangan Budaya Sekolah Berbasis Katolik" (Studi Kasus di SMP Maria Goretti Semarang) penting untuk dilaksanakan.

\section{METODE}

Penelitian ini menggunakan pendekatan kualitatif dengan rancangan studi kasus di Sekolah Menengah Pertama Katolik Maria Gorreti Semarang.Kasus yang menjadi fokus dalam penelitian ini adalah tentang pengembangan budaya sekolah berbasis agama Katolik, dilihat dari aspek: (1) proses lahirnya budaya sekolah berbasis agama Katolik, (2) nilai-nilai karakter budaya sekolah berbasis agama Katolik, (3) strategi pengembangan budaya sekolah berbasis agama Katolik, (4) faktor pendukung dan kendala yang dihadapi dalam pengembangan budaya sekolah berbasis agama Katolik, dan (5) upaya untuk meminimalisir kendala yang dihadapi dalam pengembangan budaya sekolah berbasis agama Katolik. Metode pengumpulan data dilakukan dengan teknik: (1) wawancara mendalam (indepth interview), (2) observasi partisipan (participant observation), dan (3) studi dokumentasi (study of document). Penetapan informan yang menjadi sumber data dalam penelitian ini dilakukan dengan teknikpurposive sampling, sehingga ditetapkan para sumber data dalam penelitian ini adalah: Kepala Yayasan Marsudirini daerah Poncol, Kepala SMP MGS, Wakil Kepala SMP MGS, Koordinator bidang Kesiswaan SMP MGS, dan Ketua Komite SMP MGS. Analisis data dilakukan dengan menggunakan pola interaktif Miles dan Huberman (1994). Pengecekan keabsahan data yang diperoleh dilakukan dengan menggunakan derajat kepercayaan (credibility) melalui teknik triangulasi baik sumber maupun metode.

\section{HASIL DAN PEMBAHASAN \\ Proses Lahirnya Budaya Sekolah Berbasis Agama Katolik}

Proses lahirnya budaya sekolah berbasis Katolik di SMP MGS yaitu sejak kedatangan para suster OSF misionaris ke Indonesia di Gedangan Semarang, pada tanggal 5 Februari 1870. Mereka mengadakan persiapan dan pembangunan 
untuk segala sesuatu terkait dengan sarana prasarana dalam melanjutkan karyakaryanya. Mereka bertugas mengurus anakanak yatim piatu dan memberi pendidikan keterampilan dan pelatihan bahasa Belanda pada anak Indo-Eropa. Kemudian seiring perkembangan zaman dan tuntutan pendidikan bagi anak-anak Indo Eropa dan kebutuhan pendidikan masyarakat sekitar, para suster OSF pada tanggal 1 Agustus 1871 secara resmi membuka pendidikan formal. Pada tanggal 5 Juli 1945, suster OSF mendirikan Yayasan Marsudirini sebagai yayasan yang bergerak di dunia pendidikan. SMP MGS yang berdiri pada Tahun 1952 merupakan sekolah katolik di bawah naungan Yayasan Marsudirini. Budaya sekolah katolik terbentuk dari para pendirinya yaitu Ibu Magdalena Daemen, tokoh pendiri Hakekat Konggregasi OSF. Selain itu, Yayasan Marsudirini meneladani Santo Fransiskus Assisi dan Santa Maria sebagai panutan sebagai pembentukan budaya Katolik dalam penanaman pendidikan karakter disekolah. Seiring pergantian kepala SMP MGS, pembentukan visi dan misi sekolah disesuaikan dengan visi Yayasan Marsudirini, visi dan misi yayasan di rumuskan oleh ketua yayaysan dan tim, sedangkan visi dan misi sekolah di rumuskan oleh suster kepala sekolah dan bagian pengembangan sekolah serta selalu di evaluasi setiap lima tahun sekali. Sehingga pada tanggal 23 Juni 2009 terciptanya pelajaran Kemarsudirinian yang diresmikan oleh Bapak Uskup Keuskupan Agung Semarang dan Suster Provinsial OSF ini merupakan nilai-nilai kepribadian dari para pendiri Hakekat Konggregasi OSF.

Proses lahirnya budaya sekolah berbasis Katolik di SMP MGS yang dikembangkan oleh para pendiri sekolah pada masa kolonial yang bersandarkan pada cita-cita luhur kemanusian agama Katolik secara turun-temurun diwariskan dan menjadi pegangan para ketua yayasan dan kepala sekolah hingga kini. Warisan budaya yang kuat tentang pentingnya menghadirkan nilai-nilai agama Katolik dalam pendidikan dipandang merupakan cara yang efektif untuk mempertahankan dan meningkatkan mutu sekolah. Warisan budaya ini menjadi acuan bagi generasi penerus Yayasan Pendidikan Marsudirini termasuk SMP MGS dalam melaksanakan pengelolaan sekolah. Robbins (1994) menyatakan bahwa organisasi yang besar akan mempunyai daya tahan terhadap perubahan budaya karena organisasi demikian cenderung mempunyai lebih banyak sub-budaya. Filosofis para pendiri organisasi biasanya memiliki dampak yang besar terhadap budaya dari organisasi tersebut, dimana mereka mempunyai visi jauh kedepan tentang bagaimana seharusnya organisasi (sekolah) menjalankan roda organisasinya agar dapat bertahan dengan berbagai perubahan jaman.

\section{Nilai-nilai Karakter Budaya Sekolah Berbasis Agama Katolik}

Nilai-nilai karakter budaya sekolah berbasis Katolik yang ada di SMP MGS sesuai dengan visi dan misi sekolah yaitu menjadi pusat pengembangan kecerdasan yang dilandasi semangat cinta kasih, oleh karena itu pendidikan karakter berupa beriman dan berakhlak mulia, berkepribadian yang utuh, cerdas, serta unggul yang paling diutamakan berlandaskan cinta kasih. Nilai-nilai karakter budaya sekolah katolik yang ada di SMP MGS, yaitu: (1) Nilai-nilai Beriman dan Berakhlak Mulia, Berkepribadian yang Utuh, Cerdas serta Unggul, meliputi: a) peserta didik memiliki sikap doa yang baik, b) peserta didik melaksanakan agamanya dengan tekun, c) peserta didik mengembangkan sikap cinta kasih terhadap sesama, d) peserta didik menghormati orang yang lebih tua, e) peserta didik menghormati orang lain yang sedang beribadah, f) peserta didik memberikan ucapan selmat hari raya kepada pemeluk agama lain yang sedang merayakan, g) peserta didik mencintai dan memelihara lingkungan sekitar, dan h) peserta didik menghormati dan menghargai milik sendiri dan milik orang lain; (2) Nilai-nilai Berkepribadian yang Utuh, meliputi: a) Peserta didik mempunyai pribadi matang, 
sehat dan rasional, b) peserta didik mengaktualisasi diri dengan menjadi diri sendiri dan mengembangkan sifat-sifat serta potensi-potensi dirinya, c) peserta didik percaya dengan kemampuan diri sendiri, dan d) peserta didik berwawasan luas dan kreatif; (3) Nilai-nilai Kecerdasan, meliputi: a) peserta didik tertib melaksanakan semua tugas dan kewajiban dengan penuh tanggung jawab, b) peserta didik patruh dan peduli terhadap budaya sekolah, c) peserta didik menggunakan bahasa yang baik, benar, dan santun, d) peserta didik membawa peralatan sekolah yang berhubungan dengan kegiatan belajar, e) peserta didik berani mengemukakan dan menggunakan waktu dengan kegiatan belajar, dan f) peserta didik tertib mengikuti semua kegiatan sekolah intakurikuler dan ekstrakulikuler; (4) Nilai-nilai Keunggulan, meliputi: a) peserta didik mampu berkomunikasi dalam bidang akademik dan nonakademik, b) peserta didik mampu menggunakan waktu secara efektif dan efisien untuk peningkatan diri, c) peserta didik memiliki daya tahan dan daya juang guna meraih cita-cita, d) peserta didik memiliki kepedulian yang tinggi terhadap sesame dan lingkungan sekitar, e) peserta didik memiliki perhatian dan cinta yang tulus terhadap orang tua, guru, karyawan, dan sesama, f) peserta didik aktif dalam berorganisasi baik dalam bidang keagamaan maupun bidang kemasyarakatan, g) peserta didik belajar dengan penuh semangat, tanggung jawab, percaya diri dan disiplin, dan h) peserta ddik terbuka terhadap kemajuan teknologi dan menggunakannya secara bijak dan kritis.

Disamping itu terdapat pula nilai-nilai pendidikan karakter, yaitu: (1) kegiatan yang menumbuhkembangkan semangat religiusitas dan kebangsaan, meliputi: a) sebelum pelajaran dimulai, peserta didik menyiapkan diri untuk berdoa dan mendengarkan Sabda Tuhan, b) berdoa Angelus/ Malaikat Tuhan, berdoa sesudah belajar dan doa yang disesuaikan dengan penanggalan liturgy (Novena, Rosario dan Adorasi), c) perayaan Ekaristi, d) Retret dan Rekoleksi, e) menyanyikan lagu kebangsaan "Indonesia Raya" dan menirukan teks Pancasila serta menyanyikan lagu-lagu Nasional, dan f) upacara hari senin dan hari besar nasional; (2) Kegiatan yang menumbuhkembangkan keutuhan kesederhanaan, dengan tidak memperkenankan para siswa untuk: a) membawa handphone, b) mengendarai kendaraan bermotor, c) menyemir rambut, d) membawa uang saku berlebihan, e) menggenakan acceesoris secara berlebihan (kalung, gelang, cincin), f) potongan rambut yang tidak sesuai dengan aturan sekolah; (3) Kegiatan yang menumbuhkembangkan semangat ber-belarasa, meliputi: a) Kolekte misa, dan b) kolekte untuk dana sosial (Lima Roti Dua Ikan, kematian, tanggap bencana alam, APP, Aksi Advent, hari pangat sedunia, dan aksi natal); (4) Kegiatan menumbuhkembangkan budaya peduli lingkungan sekitar, meliputi: a) melaksanakan piket kelas, b) meletakkan sampah pada tempatnya, dan c) jumat bersih/bakti kampus; (5) kegiatan yang menumbuhkembangkan budaya kasih, meliputi: a) membiasakan 5S (Senyum, sapa, salam, sopan dan santun), b) berjabat tangan dengan Suster, bapak/ibu guru dan karyawan, serta teman, c) mendoakan Suster, bapak/ibu guru dan karyawan, serta teman-teman yang berulang tahun, d) mengunjungi, mendoakan yang sakit dan mengalami dukacita, e) mengantar teman yang sakit ke UKS, dan f) mengadakan kunjungan ke panti asuhan, panti jompo, dan panti khusus difabel; (6) Kegiatan yang menumbuhkembangkan budaya kerapian dan keindahan, meliputi: a) berseragam rapi, b) menata/merapikan rambut, dan c) memperhatikan kebersihan diri (badan dan kuku); (7) kegiatan yang menumbuhkan rasa memiliki sekolah/cinta almamater, meliputi: a) membentuk paguyuban alumni, b) menjaga fasilitas sekolah, dan c) mendukung dan terlibat dalam program sekolah; (8) Optimalisasi layanan konsultasi dan bimbingan oleh guru BK, guru pengampu mata pelajaran serta guru wali kelas.

Nilai-nilai karakter budaya sekolah berbasis Katolik yang terdapat pada SMP 
MGStersebut di atas senada dengan pendapat Robbins (2015) bahwa budaya yang kuat dicirikan oleh nilai inti dari organisasi yang dianut dengan kuat, diatur dengan baik, dan dirasakan bersama secara luas. Syafri (dalam Dewi, 2015) juga mengungkapkan bahwa terdapat 18(delapan belas) karakter pendidikan budaya karakter bangsa yang dapat diadopsi oleh sekolah, yaitu: Religius, jujur, toleransi, disiplin, kerja keras, kreatif, mandiri, demokratis, rasa ingin tahu, semangat kebangsaan, cinta tanah air, menghargai prestasi, bersahabat/ komunikatif, cinta damai, gemar membaca, peduli lingkungan, peduli sosial, dan tanggung jawab.

\section{Strategi Pengembangan Budaya Sekolah Berbasis Katolik}

Strategi pengembangan budaya sekolah berbasis Katolik yang dilakukan oleh SMP MGS dilakukan melalui 2 (dua) strategi, yaitu: a) Strategi yang ditujukan bagi guru dan tenaga kependidikan, meliputi: (1) adanya rapat kerja gabungan wilayah poncol setiap awal tahun ajaran baru yang dipimpin oleh Kepala Penanggung Jawab Yayasan Marsudirini Wilayah Poncol, (2) adanya buku Jambon atau buku agenda kegiatan guru yang akan diperiksa dan ditandatangani oleh Suster kepala sekolah seminggu sekali, dan c) adanya doa pagi dan briefing untuk semua guru dan staf SMP MGS sebelum peserta didik datang kesekolah; b) Strategi yang ditujukan bagi peserta didik, meliputi: (1) sosialiasi tentang tata tertib, budaya sekolah dan program tahunan sekolah yang di laksanakan di awal tahun ajaran baru, (2) terbitnya model pembelajaran Marsudirini yang bertujuan mengenal, mengerti, memahami, serta meneladani kehidupan Ibu Magdalena Daemen, dan Santo Fransiskus Assisi, (3) adanya simbolsimbol Katolik berupa patung Ibu Magdalena Daemen, patung Santa Maria Goretti, patung Santo Fransiskus Assisi dan salib yang ada korpusnya, (4) mengaktifkan dan mewajibkan kembali ekstrakulikuler pramuka, (5) membiasakan kegiatan- kegiatan sekolah seperti doa pagi, mendengarkan Sabda Tuhan, menyanyikan lagu kebangsaan "Indonesia Raya", menirukan teks Pancasila, menyanyikan lagu-lagu nasional serta upacara hari senin dan hari besar nasional, (6) melaksanakan kegiatan pembinaan peserta didik secara periodik yang dilaksanakan dua kali dalam satu semester di aula sekolah, (7) melaksanakan pengembangan peserta didik berupakegiatan luar sekolah seperti Wisata Rohani untuk kelas VII, Wisata dan Rekoleksi untuk kelas VII, dan Retret serta Motivasi persiapan Ujian untuk kelas IX.

Strategi pengambangan budaya sekolah berbasis Katolik yang dilakukan oleh SMP MGS senada dengan pendapat Spradley (dalam Siswanto, 2017) yang menyebutkan komponen kultur yang mempengaruhi perkembangan kultur meliputi: (1) komponen tingkah laku kepala sekolah, guru, siswa, dan tata usaha sekolah, (2) komponen kultur artifak meliputi dokumen, prestasi, dan barang/benda/lambing, dan (3) komponen speech message, meliputi aturan/tata tertib, larangan, spirit, dan nilai-nilai. Zamroni (2005) menyebutkan syarat pertama dalam pengembangan kultur sekolah adalah kepemimpinan atau sekelompok orang yang memiliki kesadaran, kemauan, dan komitmen untuk mengembangkan gagasangagasan baru yang kemudian dirumuskan kedalam visi, misi dan tujuan kedalam langkah-langkah dan aksi kongkrit, yang dikaitkan dengan pola dasar asumsi yang tidak cocok atau relevan, berarti pola dasar ini harus diubah dengan pola dasar asumsi yang baru.

\section{Faktor Pendukung dan Kendala yang Dihadapi dalam Pengembangan Budaya Sekolah Berbasis Agama Katolik}

Faktor pendukung dalam pengembangan budaya sekolah berbasis Katolik pada SMP MGS, meliputi: a) ketersediaan sumber daya manusia (tenaga pendidik dan kependidikan) yang berkualitas agar dalam mentransfer ilmu lebih mudah dipahami peserta didik, b) kerjasama yang harmonis dari suster, guru- 
guru, dan orang tua memberikan teladan dalam menumbuhkan budaya katolik, c) sarana dan prasarana yang memadai dalam mendukung program pengembangan budaya sekolah. Sedangkan kendala yang menghambat dalam pengembangan budaya sekolah berbasis Katolik, meliputi: a) watak/karakter peserta didik yang beragam akibat dari lingkungan keluarga, sehingga watak peserta didik ada yang lebih sensitif, pemarah, pemberontak, suka memukul teman, dan keras kepala membuat budaya sekolah sulit untuk dikembangkan, b) kurangnya kontrol/perhatian orang tua terhadap aktivitas peserta didik dirumah karena waktu peserta didik lebih lama berada dirumh membuat peserta didik sering kecanduan bermain gadget sehingga lupa waktu untuk belajar, tidak mengerjakan PR, tidak konsentrasi ketika jam pelajaran, acuh kepada teman dan suka menyendiri.

\section{Upaya Meminimalisir Kendala yang Dihadapi dalam Pengembangan Budaya Sekolah Berbasis Katolik}

Upaya yang dilakukan untuk meminimalisir berbagai kendala yang di hadapi dalam pengembangan budaya sekolah berbasis Katolik di SMP MGS, yaitu: a) jika peserta didik terus menerus melanggar tata tertib maka peserta didik dan orang tua akan dipanggil oleh wali kelas lalu kemudian ke guru BK, jika pelanggaran berat maka akan di arahkan kepada kepala sekolah untuk di introgasi mengapa terus menerus melakukan pelanggaran tata tertib, b) wali kelas akan terus menerus mengingatkan orang tua untuk selalu mengontrol peserta didik ketika berada di rumah melalui grup-grup media sosial kelas, c) sosialisasi mengenai program kerja sekolah yaitu mengadakan beberapa kegiatan ekstrakulikuler dan bimbingan belajar untuk meningkatkan prestasi peserta didik.

Upaya yang dilakukan oleh SMP MGS untuk meniminalisir berbagai kendala yang dihadapi sejalan dengan pendapat Fletcher (dalam Siswanto, 2017) bahwa dalam upaya meminimalisir berbagai kendala yang dihadapi dalam pengembangan budaya sekolah dapat dilakukan dengan berkoborasi dengan berbagai pihak terkait seperti orang tua dan masyarakat serta stakeholder lainnyakarena kolaborasi tersebut merupakan cara yang positif dan efektif dalam pengembangan kultur sekolah yang pada akhirnya akan memberikan manfaat bagi semua pihak.

\section{SIMPULAN}

Berdasarkan hasil penelitian dan pembahasan yang telah diuraikan sebelumnya, dapat dirumuskan kesimpulan sebagai berikut:

1. Proses lahirnya budaya sekolah berbasis Katolik di SMP MGS yang dikembangkan oleh para pendiri sekolah pada masa kolonial yang bersandarkan pada cita-cita luhur kemanusian agama Katolik secara turun-temurun diwariskan dan menjadi pegangan para ketua yayasan dan kepala sekolah hingga kini. Warisan budaya yang kuat tentang pentingnya menghadirkan nilai-nilai agama Katolik dalam pendidikan dipandang merupakan cara yang efektif untuk mempertahankan dan meningkatkan mutu sekolah. Warisan budaya ini menjadi acuan bagi generasi penerus Yayasan Pendidikan Marsudirini termasuk SMP MGS dalam melaksanakan pengelolaan sekolah.

2. Nilai-nilai karakter budaya sekolah berbasis agama Katolik yang ada di SMP MGS adalah Nilai-nilai Beriman dan Berakhlak Mulia, dan Berkepribadian yang Utuh, Cerdas serta Unggul berlandaskan cinta kasih.

3. Strategi pengembangan budaya sekolah berbasis agama Katolik yang dilakukan oleh SMP MGS adalah dilakukan dengan 2 strategi, yaitu: a) strategi yang ditujukan bagi guru, melalui: 1) rapat koordinasi dan evaluasi rutin gabungan sekolah yang dilakukan pihak yayasan Marsudirini, 2) penerapan buku Jambon yang diperiksa oleh kepala sekolah setiap minggu, dan 3) pembiasaan doa bersama dan briefingsemua guru dan staf sebelum jam sekolah dimulai; b) strategi 
yang ditujukan bagi peserta didik, meliputi: 1) sosialisasi tata tertib, budaya sekolah dan program tahunan sekolah pada awal tahun ajaran baru, 2) penerapan model pembelajaran Marsudirini, 3) pemajangan simbolsimbol agama Katolik pada setiap sudut sekolah, 4) pewajiban bagi peserta didik untuk mengikuti ekstrakurikuler pramuka, 5) pembiasaan doa pagi, mendengarkan pembacaan sabda Tuhan, menyanyikan lagu Indonesia Raya dan pembacaan teks Pancasila serta menyanyikan lagu-lagu nasional setiap upacara senin dan hari besar nasional, dan 6) melaksanakan pengembangan karakter peserta didik melalui kegiatan seperti wisata rohani, studi wisata dan rekoleksi bagi kelas VII, serta retret dan motivasi persiapan ujian untuk kelas IX.

4. Faktor pendukung dalam pengembangan budaya sekolah berbasis Katolik pada SMP MGS, meliputi: a) ketersediaan sumber daya manusia (tenaga pendidik dan kependidikan) yang berkualitas agar dalam mentransfer ilmu lebih mudah dipahami peserta didik, b) kerjasama yang harmonis dari suster, guru-guru, dan orang tua memberikan teladan dalam menumbuhkan budaya katolik, dan c) sarana dan prasarana yang memadai dalam mendukung program pengembangan budaya sekolah. Sedangkan kendala yang menghambat dalam pengembangan budaya sekolah berbasis Katolik, meliputi: a) watak/karakter peserta didik yang beragam akibat dari lingkungan keluarga, sehingga watak peserta didik ada yang lebih sensitif, pemarah, pemberontak, suka memukul teman, dan keras kepala membuat budaya sekolah sulit untuk dikembangkan, b) kurangnya kontrol/perhatian orang tua terhadap aktivitas peserta didik dirumah karena waktu peserta didik lebih lama berada dirumh membuat peserta didik sering kecanduan bermain gadget sehingga lupa waktu untuk belajar, tidak mengerjakan PR, tidak konsentrasi ketika jam pelajaran, acuh kepada teman dan suka menyendiri.

5. Upaya yang dilakukan untuk meminimalisir berbagai kendala yang di hadapi dalam pengembangan budaya sekolah berbasis Katolik di SMP MGS, dilakukan melalui cara: a) jika peserta didik terus menerus melanggar tata tertib maka peserta didik dan orang tua akan dipanggil oleh wali kelas lalu kemudian ke guru BK, jika pelanggaran berat maka akan di arahkan kepada kepala sekolah untuk di introgasi mengapa terus menerus melakukan pelanggaran tata tertib, b) wali kelas akan terus menerus mengingatkan orang tua untuk selalu mengontrol peserta didik ketika berada di rumah melalui grup-grup media sosial kelas, c) sosialisasi mengenai program kerja sekolah yaitu mengadakan beberapa kegiatan ekstrakulikuler dan bimbingan belajar untuk meningkatkan prestasi peserta didik.

\section{UCAPAN TERIMA KASIH}

Ucapan terima kasih penulis sampaikan kepada pihak SMP Maria Gorreti Semarang yang telah memberikan ijin dan kemudahan proses selama berlangsungnya kegiatan penelitian, serta Redaksi Equity in Education Journal (EEJ) yang telah memberikan kesempatan artikel kami dapat dimuat dalam jurnal ini.

\section{DAFTAR PUSTAKA}

Danim, S. (2007). Visi Baru Manajemen Sekolah. Jakarta: Bumi Aksara.

Daryanto. (2015). Pengelolahan Budaya \& Iklim Sekolah. Yogyakarta: Gava Media.

Departemen Pendidikan Nasional (Depdiknas). (2007). Manajemen Berbasis Sekolah. Jakarta: Ditjen Dikdasmen Direktorat Pembinaan Pendidikan Sekolah Menengah Pertama.

Dewi, M. P. R. (2015). Internalisasi Budaya Sekolah Berbasis Islam (Studi Kasus di Madrasah Tsanawiyah Negeri 1 Model Palangka Raya). Skripsi tidak 
Equity in Education Journal (EEJ), Vol. 1, No. 1, Oktober 2019

dipublikasikan, Universitas

Palangka Raya: Program Studi Manajemen Pendidikan.

Dewi, R. N. L. (2015). Motivasi Orang Tua Memilih Sekolah Berbasis Agama di MI Tahassus Prapagkidul Kecamatan Pituruh Kabupaten Purworejo.Skripsi tidak dipublikasikan, Universitas Negeri Yogyakarta: Program Studi Pendidikan Guru Sekolah Dasar.

Hafidhuddin, D., \& Tanjung, H. (2003). Manajemen Syariah dalam Praktik. Jakarta: Gema Insani.

Husni, M. (2015). Budaya Sekolah dan Peningkatan Mutu Pendidikan. Diakses pada 25 Agustus 2018 dari: https://www.academia.edu/2856902 9/Budaya_Sekolah

Dan_Peningkatkan_Mutu_Pendidik an.

Miles, Matthew, B. \& Huberman, A. M. (1994). Analisis Data Kualitatif Buku Sumber Tentang MetodeMetode Baru. Jakarta: UI-Press.

Robbins, S. P. (1994). Teori Organisasi Struktur, desain \& Aplikasi. Jarkarta: Arcan.

Robbins, S. P. (2015). Perilaku Organisasi. Jakarta: Penerbit Salemba Empat.

Siswanto. (2017). Apa dan Bagaimana Mengembangkan Kultur Sekolah. Klaten: Bosscript.

SMP Maria Gorreti. (2017). Panduan Akademik dan Budi Pekerti SMP Maria Gorreti Semarang. Diakses pada 27 Maret 2018 dari: http://smpmariagoretti.sch.id/ panduanakademikdanbudipekerti.

Sonhadji, A. (2007). Optimalisasi dalam Rangka Penjaminan Mutu Program Studi S1 PGSD. Makalah disajikan pada Workshop Optimalisasi Tata Pamong S1 PGSD Universitas PGRI Adi Buana Surabaya, 14 September 2007.

Sonhadji, A. (2012). Manusia, Teknologi, dan Pendidikan Menuju Peradaban Baru. Malang: Penerbit Universitas Negeri Malang.
Sudrajat, A. (2010). Pengembangan Budaya Sekolah. Diakses tanggal 28 Agustus 2018 dari: https://akhmadsudrajat.wordpress.c om/2010/03/04/manfaat-prinsipdan-asas-pengembangan-budayasekolah/comment-page-.

Sunyoto, G. (2010). Sekolah Katolik dalam Harapan Gereja dan Masyarakat. Jurnal Pendidikan Agama Katolik, Vol. 3(2).

Syafei, M. S. (2006). Bagaimana Anda Mendidik Anak: Tuntunan Praktis Orang Tua dalam Mendidik Anak. Bogor: Ghalia Indonesia.

Tilaar, H. A. R. (2000). Paradigma Baru Pendidikan Nasional. Jakarta: PT. Rineka Cipta.

Tirtahardja, U., \& Sulo, S. (2005). Pengantar Pendidikan. Jakarta: PT. Rineka Cipta.

Zamroni. (2005). Paradigma Pendidikan Masa Depan. Yogyakarta: Bayu Indra Grafika. 